\title{
Comparison of the retentive ability on incisal bite force between aloe vera and poly(methyl-vinyl-ether) adhesive materials in complete acrylic denture measured by modified pressure transducer
}

\author{
Marisa Julinda ${ }^{1}$, Taufik Sumarsongko ${ }^{2 *}$, Gian Nur Alamsyah², Aprillia Adenan² \\ 'Division of Prosthodontics Treatment, Oral Health Clinics Syarif Hidayatullah State Islamic \\ University Hospital, Indonesia \\ ${ }^{2}$ Department of Prosthodontics, Faculty Dentistry Universitas Padjadjaran, Indonesia
}

\begin{abstract}
Introduction: Patients with acrylic complete denture, usually have a confidence issue in using their complete dentures to chew and speak, because of concern about detached of the denture from its place and pain on the alveolar ridge. Application denture adhesive material ordinarily can solve the problem. Mostly, denture adhesives in the market are made from synthetic material poly(methyl-vinylether) but nowadays aloe vera extract is believed to be a substitute to synthetic denture adhesive material. The purpose of this study was to analyzed of comparison the retentive ability on incisal bite forces between aloe vera extract and poly(methyl-vinyl-ether) adhesive in complete acrylic denture ameasured by modified pressure tranducer. Methods: This true-experimental research used 10 samples from patients who used acrylic complete denture and meet suitable criteria. Samples were tested in three different interventions, the first one applied by denture adhesive made from poly(methyl-vinylether), the second one applied by denture adhesive made from aloe vera extract and the third one as a control group, sample was tested without any application of denture adhesive. Retentive ability on incisal bite forces was measured by modified pressure transducer with integrated software. Data was analysis using ANOVA method. Results: Anterior bite force as control 20,98 N, aloe vera 23,42 N, poly (methyl-vinyl-ether) $21,25 \mathrm{~N}$ and without denture adhesive as control. Significant differences in the incisal bite force dislodgement of dentures that were applied with Aloe vera-based denture adhesive $\mathrm{s}$ with p-value of 0.0088 . Conclusion: Denture adhesive made from Aloe vera extract had the highest adhesiveness incisal bite force value compared to denture adhesive made from poly(methyl-vinyl-ether) and without denture adhesive.
\end{abstract}

Keywords: retentive ability; incisal bite force; aloe vera; poly(methyl-vinyl-ether); pressure transducer.

p-ISSN: 1979-0201; e-ISSN: 2549-6212; Available from: http://jurnal.unpad.ac.id/pjd/article/view/23907

DOI: 10.24198 /pid.vol33no1.23907

Submission: Oct 14, 2019; Accepted: Jan 05, 2021; Published online: Mar 31, 2021

*Corresponding author: Taufik Sumarsongko, Department of Prosthodontics, Faculty of Dentistry Universitas Padjadjaran, Indonesia. Jalan Sekeloa Selatan I, Bandung, West Java, Indonesia, 40132. Phone: +62 811-222-018;

e-mail: taufik.sumarsongko@fkg.unpad.ac.id 


\section{INTRODUCTION}

Mastication process decreases with the loss of teeth, as well as in patients who use complete denture. In patients with complete denture, maximum bite force is much lower than in patients with natural teeth. The magnitude of the bite force is also allegedly influenced by other factors, including pain threshold, mucosal sensitivity, emotional state, and force distribution. In patients with tooth loss conditions, there are several factors that affect the ability of mastication, among others modification of support area, functional and parafunctional movements, change in the facial length, and good response in adapting to change. ${ }^{1,2,3}$ Bite force is one indicator of a good mastication system. Bite force is produced due to movement of muscles that move the lower jaw. Bite force is used as an indicator to evaluate the function of mastication on complete denture wearers, this is to assess the extent to which complete denture can serve as a therapeutic tool for patients who have lost teeth. Some of the things that influence the assessment of bite force are cranio-fascial morphology, age, sex, and presence of temporomandibular joint disorder. ${ }^{4}$

Complete denture-incisal bite force is a bite force that can be received by complete denture in the incisal region, until the release on the dorsal portion of the complete denture. ${ }^{5}$ Complete denture-incisal bite force can be improved by making a good adaptation between complete denture and underlying mucosa. This is also due to the well-keratinized ridge, has a good anatomical shape (square, broad, high alveolar bone in the absence of undercut). This is due to the movement of the condyle down and forward. This movement will cause complete denture instability in the posterior part, and cause complete denture dislodgement of the underlying tissue. This can be avoided by considering the balance occlusion in the posterior region at the time of excursion. ${ }^{1,2,3}$

Support factor that leads to better complete denture retention. There are three supporting factors involved in complete denture retention, which are maximum expansion of denture base; expansion of maximum contact area between soft tissue and denture base; and good adaptation between denture base and basal seat. ${ }^{1,2}$ Retention is ability to withstand release force (dislodgment).
Denture movement is a movement of vertical direction and away from the area that supports it (denture bearing area). Many scholars believe that retention is influenced by a good adaptation between the denture base and the soft tissue supporting the denture. This is an important factor for the realization of adhesive retention, frictional or atmospheric retention. Retention is an absolute requirement for denture..$^{5,6,7,8}$

Adhesion is obtained from the attraction between two molecules of different types, the oral mucosa and the saliva molecule. Cohesion is the retention obtained by the forces between two similar molecules, namely intra-saliva molecules. $5,6,7$ Denture adhesive is an adhesive material between an acrylic-based denture with mucosa consisting of various types of preparations. ${ }^{8}$ The use of denture adhesive is expected to improve stabilization and retention of denture so that the patient can chew and speak well, this will certainly improve the quality of life of patients. ${ }^{2,9}$

Attachment mechanisms between soft tissue and denture adhesive by chemical and physical mechanisms, where one of the elements contained in the adhesive denture will expand and suck the water until it becomes sticky and thick. This will improve retention by optimizing the surface tension, cohesive and adhesive properties between the anatomical surface of the denture complete with the soft tissue underneath.

Denture adhesive based on the ingredients of manufacture, classified into two types, namely herbs and synthetics. Denture adhesive herbs used before the beginning of 1960 , which is based on the sap of vegetables, such as karaya, tragakan, xhantan and acacia. In synthetic type adhesive denture, it consists of salts that act as polymers. The American Dental Association reports that this type of synthetic adhesive denture is well received by dentists. ${ }^{2,10,11}$

Denture-based adhesive herbs, including denture adhesives based on aloe vera, some of the advantages. Empirically, aloe vera has traditionally been widely used as a medicinal substance, while synthetic denture adhesives are poly(methyl-vinyl-ether)..$^{11,12}$ The active ingredients in aloe vera that adhere to the role are the Acemannan polysaccharide obtained from aloe vera gel, mainly composed of glucomannan as well as a small amount of arabinan and galactan. 
The monosaccharides are D-glucose, D-mannose, arabinose, galactose and xylose. ${ }^{13}$ The purpose of this study was to analyzed of comparison the retentive ability on incisal bite forces between aloe vera extract and poly(methyl-vinyl-ether) adhesive in complete acrylic denture ameasured by modified pressure tranducer. ${ }^{14}$

\section{METHODS}

This study was an experimental study conducted on complete denture patients, after a 6-8 week control. The study population was the patient who came to the Prosthodontic Clinics of Universitas Padjadjaran Dental Hospital, after the adjustment period according to the inclusion criteria each patient was given 3 different treatments. The sampling method used was accidental sampling.

\section{Inclusion criteria}

The inclusion criteria from this study sample are patients with full edentulous teeth on both arches and using complete acrylic denture use post-dam seal on 2-3 mm wide jaw and 0.5-1 mm depth along the Ah line, with posterior beaded palatal seal design (Figure 1$)^{15,16}$. Patients also have no history of using denture adhesive and have moderate alveolar ridge height.

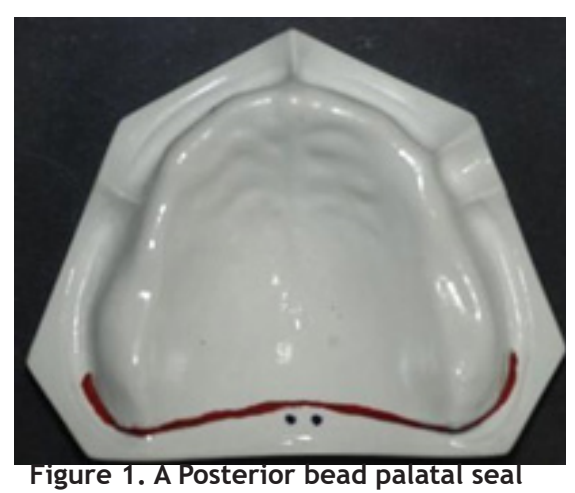

The exclusion criteria of this study were the existence of a history of medications that interfere with the system in the mouth, such as radiotherapy treatment, as well as medical problems that will interfere with patients being present in the study.

Examination was done in the posterior and anterior region.(1) Deep-vestibulum: when the mouth mirror sits more than half the diameter. (2) shallow vestibulum: when the mouth mirror is immersed less than half the diameter. Inclusion criteria are the patients show a good response of complete denture care after the adjustment period, visible retention and good stabilisation and comfortable in using. Patients has good general health, so patients can be present in research in a prosthodontics clinic. No history of allergic sensitivity to any component used in this experiment. Patients may comply with research procedures and research objectives in accordance with ethically approved informed consent. ${ }^{16}$

This study was a clinical experimental study to compare retentive ability in incisal bite force using 2 types of denture adhesive, aloe vera based and poly(methyl-vinyl-ether) applied to complete acrylic imitation teeth with posterior palatal seal design. 10 patients were consisting of 4 men and 6 women, aged between 40-60 years. Patients included in the inclusion criteria were patients who had used maxillary and lower jaw teeth for 6-8 weeks (in the control visit). All patients chosen as sample by accidental sampling method.

\section{Instruments and materials}

The instruments and materials of this research were as follows: (1) The material applied to the anatomical surface of complete denture of acrylic in this research was denture adhesive material, consisted of two kinds of finished product, Poly (methyl-vinyl-ether) and aloe vera based denture adhesive. (2) The measuring instrument used was a pressure transducer.

The examination was carried out using a pressure transducer that converts mechanical energy into electrical energy, which was used to record the patient's bite force until dislodgment incisal bite force occurs on the dorsal part of the maxillary denture plate. This instrument was a modification of the pressure transducers used in engineering and machinery, made in such a way as to measure the patient's incisal bite force directly (intraoral).

Previous studies on incisal bite force by Kalra et al. ${ }^{13}$ stated that a gnathometer was used to measure the bite force of a patient. However, this instrument could not interpret the bite force's results in the Newton units, thus, a modification on the pressure transducer must be conducted. The pressure transducer modified in the Electrical Laboratory of Malang State Polytechnic by lecturers of Malang State Polytechnic (Figure 2). 


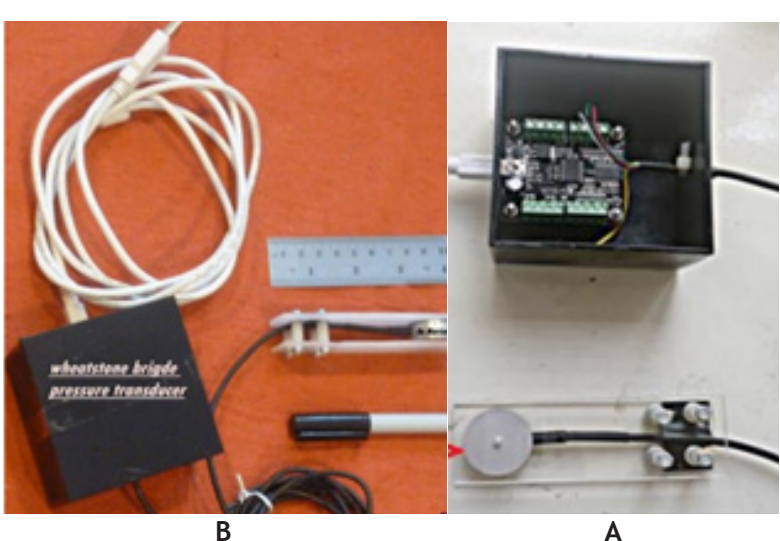

Figure 2.A) Pressure Transducers tool, incisal bite power recorder; B) Measure Pressure Transducer tool that will record the strength of the patient's bite, connected to the computer

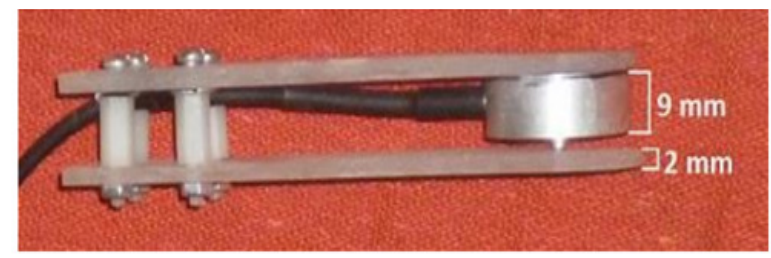

Figure 3. Pressure Transducer

\section{Research procedure}

Furthermore, the incisal bite force was measured. The incisal bite force of complete denture applied with an adhesive denture based on Aloe vera and Poly (methyl-vinyl-ether) was measured using a tool that can test the retention and denture stabilization using Pressure Transducer tool. ${ }^{18}$ (Figure 3).

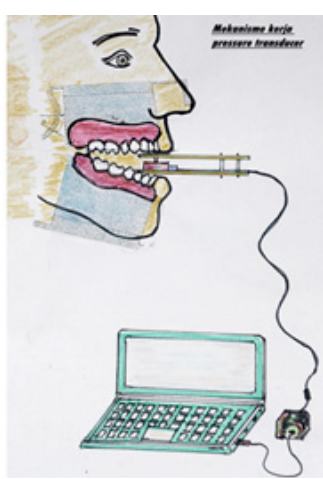

A

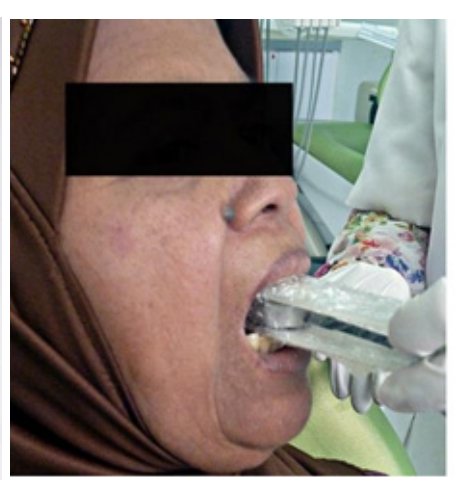

B
Figure 4. a) Mechanism of measuring instrument Pressure Transducers that will brand the patient's dental strength b) Measuring tools mounted between the anterior teeth above and below the complete artificial tooth

The measurement steps were conducted by initially measured a complete denture of a patient for the incisal bite force without adhesive denture using pressure transducers. The patient then instructed to use aloe vera-based adhesive denture in accordance with factory rules on complete dentures, then the patient was required to bite and recorded the patients bite force with pressure transducers, then complete denture was cleaned, and the patient was asked to use poly (methyl-vinyl-ether) in accordance with factory rules, then re-measurement using pressure transducers (Figure 4).

\section{Data analysis technique}

Testing to assess differences between incisal bite forces of the three treatment groups was carried out using the ANOVA method. If test results show a $p$-value $>0.1$, then the value of a difference that is not statistically significant.

\section{RESULTS}

\section{Maximum incisal bite force}

The maximum incisal bite force was the maximum force of the incisal bite achieved until the release of the post-dam palatal seal. This value was obtained from the highest value when the patient bites the load- cell type button pressure transducers until there was complete denture rupture in the dorsal frame. Comparison of maximal incisal bite styles can be described in Figure 1 and Table 1.

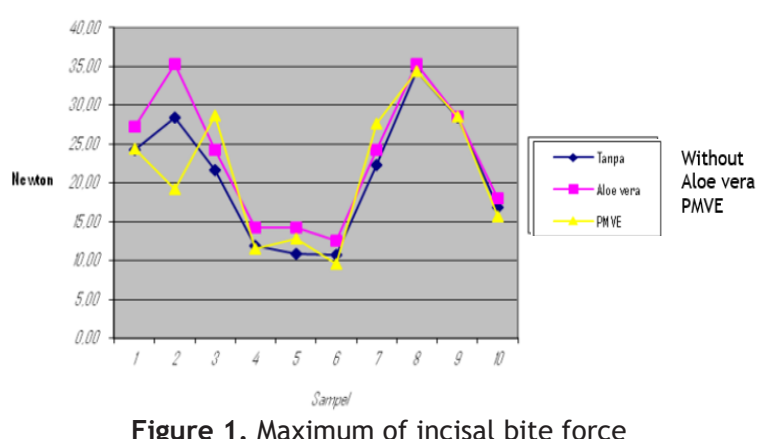

Figure 1 and Table 1 present the maximum load value $(\mathrm{N})$ that occur in three groups of samples. The mean value of the three groups aloe vera denture base, poly-(methyl-vinyl-ether) denture base, and without denture adhesive base\} can be measured. The mean value of maximum incisal bite force of the three groups showed that the group that complete denture using Aloe vera-based denture adhesive had a higher mean compared to the group of patients using poly(methyl-vinylether) or groups of patients without using denture adhesive. However, it appears that the maximum 
incisal bite force on complete dentures that are given denture adhesive based on aloe vera and poly(methyl-vinyl-ether) was higher than that of acrylic complete dentures that were not given the application of denture adhesive.

Table 1. Maximum incisal bite force

\begin{tabular}{cccc}
\hline Denture adhesive & $\begin{array}{c}\text { Mean } \\
\text { (Newton) }\end{array}$ & $\mathrm{n}$ & Std. dev \\
\hline $\begin{array}{c}\text { without denture } \\
\text { adhesive }\end{array}$ & 20.98 & 10 & 8.2322 \\
Aloe vera & 23.42 & 10 & 8.4552 \\
Poly(methyl-vinyl-ether) & 21.25 & 10 & 8.6246 \\
\hline
\end{tabular}

\section{Incisal bite dislodgement force}

Incisal bite dislodgement force is the comparison of the bite force when a complete maxillary denture is dislogment on the dorsal part of palatal.

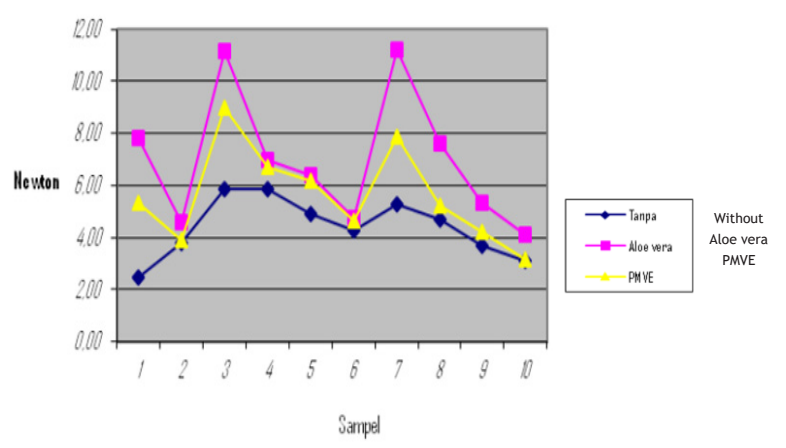

Figure 2. Incisal bite dislodgement force

Table 2. Incisal bite dislodgement force

\begin{tabular}{cccc}
\hline Denture adhesive & $\begin{array}{c}\text { Mean } \\
\text { (Newton) }\end{array}$ & $\mathrm{n}$ & Std. Dev \\
\hline $\begin{array}{c}\text { without denture } \\
\text { adhesive }\end{array}$ & 4.41 & 10 & 1.1408 \\
$\begin{array}{c}\text { Aloe vera } \\
\text { Poly(methyl-vinyl- } \\
\text { ether) }\end{array}$ & 5.60 & 10 & 2.5452 \\
\hline Total & 5.67 & 30 & 2.1491 \\
\hline
\end{tabular}

Figure 2 and Table 2 showed the mean value of the dislodgment of the three groups. Complete denture group using Aloe vera-based denture adhesive had a higher mean compared to the group of patients using poly(methyl-vinyl-ether) denture adhesive and group without using denture adhesive.

\begin{tabular}{cccc}
\multicolumn{4}{c}{ Tabel 3. Result of ANOVA (P-Value) } \\
\hline $\begin{array}{c}\text { Denture } \\
\text { adhesive }\end{array}$ & $\begin{array}{c}\text { Without } \\
\text { denture } \\
\text { adhesive }\end{array}$ & $\begin{array}{c}\text { Poly } \\
\text { (methyl-vinyl- } \\
\text { ether) }\end{array}$ & $\begin{array}{c}\text { Aloe } \\
\text { vera }\end{array}$ \\
\hline $\begin{array}{c}\text { No denture } \\
\text { adhesive }\end{array}$ & 0.0924 & 0.0088 \\
\hline $\begin{array}{c}\text { Poly } \\
\text { (methyl-vinyl- } \\
\text { ether) }\end{array}$ & 0.0924 & & 0.1828 \\
\hline Aloe vera & $\mathbf{0 . 0 0 8 8}$ & $\mathbf{0 . 1 8 2 8}$ & \\
\hline
\end{tabular}

Table 3 shows the value of the difference in incisal bite force dislodgement. Highly significant shown by the ANOVA measurements between Aloe vera-based denture adhesives group against without denture adhesive group ( $\mathrm{P}$-Value $<0.05)$. Other results showed that there was no significant difference between complete dentures treated with Aloe vera based denture adhesive compared to poly-based denture adhesive poly(methyl-vinylether), as well as complete denture treated with poly-based denture adhesive poly(methyl-vinylether) compare to the group without denture adhesive.

\section{DISCUSSION}

In this study, test and control samples consisted of complete acrylic denture wearers using a posterior beaded palatal seal design. Then the complete denture of selected acrylic was treated using denture adhesive based on aloe vera, poly (methyl-vinyl-ether) and without treatment as control.

Testing was done by means of pressure transducers that will change the mechanical power into electric power. In this study, test and control samples in the form of complete denture made from acrylic resin were observed in the retention capability of the incisal bite force.

Tests are carried out using a pressure transducer that can convert mechanical energy into electrical energy, which is used to record the strength of the patient's bite, until dislodgement incisal bite force occurs on the dorsal plate of the maxillary denture. This measuring instrument records the strength of the bite in Newton units.

The principle of the tool used in this study is similar to the tool used in the study used by Kalra et $\mathrm{al}^{13}$, but different from the tools used in previous studies of incisal bite force. Kalra et al. 
state that previous research used a device called a gnathometer to measure the bite strength of patients, ${ }^{13}$ but this tool could not interpret the results of the bite strength measured in Newton units.

Koc et al. ${ }^{4}$ stated that the tool for examining the bite force (bite force) that was considered the most comfortable for patients was the transducer. The results of maximum incisal bite force measurement in patients using complete dentures in a group of patients without the application of denture adhesive, patients using complete dentures who are given the application of dentures based on Aloe vera and patients using complete dentures who are given the application of dentures based on poly(methyl-vinyl-ether) shows that the maximum value of the maximum incisal bite force in patients using complete acrylic dentures without using denture adhesive is lower than patients with denture adhesive applications.

Further analysis to compare differences in the maximum incisal bite force in patients using acrylic complete dentures treated with aloe vera, poly(methyl-vinyl-ether) based denture adhesives and without treatment, showed that there were no statistically significant differences. The difference between complete denture without the application of denture adhesive and complete dentures given the application of dentures made from aloe vera and poly (methyl-vinyl-ether) shows that the maximum incisal bite force in these three conditions is not too much difference. The results of this measurement show that the application of denture adhesive increases incisal bite force in patients using acrylic complete denture, but not statistically significant.

From the mean value of the incisal bite force of the complete acrylic denture obtained, it can be seen that the maximum incisal bite force of the complete acrylic denture is $21.88 \mathrm{~N}$ in the Malay race. The results obtained from this study are smaller than those obtained by Boucher et al. ${ }^{1}$

Study conducted by Zarb et al. ${ }^{2}$ suggested that the maximum incisal bite force (maximum bite force) acceptable to complete dentures ranges from 13 to $16 \mathrm{lb}$ (6 to $8 \mathrm{~kg}$ ) or even smaller, this value is equivalent to $50-70 \mathrm{~N}$. But in the book they wrote, the sample taken was the Caucasoid race, which most likely also had an effect on the size of the bite force.

This previous study also did not mention which part of the complete acrylic denture was studied. According to Woller et al. ${ }^{4}$ that the more posterior, the biting force will increase. Zarb and George et al.1,2 also state that the natural teeth bite force is $44 \mathrm{lb}(20 \mathrm{~kg})$ or equivalent to 196.13 $\mathrm{N}$. These results indicated that it is approximately three times from the bite force of acrylic complete dentures. The retentive ability of the use of acrylic dentures can be seen from the incisal bite force of the release and the length of time needed until the release occurs. Test results on the release of the incisal bite force showed that the average incisal bite force removal in the group of patients using complete denture using aloe verabased denture adhesive was better, compared to the group of patients using poly-based denture adhesive (methyl-vinyl-ether).

Further analysis showed that the mean difference of each group was significant. Moreover, a very significant difference was found between the bite force of the release incisal on the application of aloe vera-based denture adhesive towards the acrylic complete dentures to acrylic complete dentures without being treated. However, the difference was not significant between release incisal bite force in aloe vera based denture adhesive applications compared to poly(methylvinyl-ether) denture adhesive applications.

These differences were also supported by the properties of the basic ingredients of the denture adhesive. Research conducted by Fuentes et al. ${ }^{15}$ revealed that aloe vera gel contains $98.5 \%$ 99.5\% water. The content of polysaccharides, which are active ingredients in aloe vera, found in as much as $60 \%$ of the total solid content in aloe vera.

From this information, the researchers assume that polysaccharides are substances that are soluble in water. Water-soluble materials require special treatment, in order to obtain the desired consistency and shape. This effort will needed to reduce the level of water solubility. Nowadays, material with the ability to not dissolve quickly in water still requires quite expensive costs. Therefore, the price of denture adhesives on the market is also higher compared to dentures based on poly (methyl-vinyl-ether). 


\section{CONCLUSION}

Denture adhesive made from Aloe vera extract had better adhesiveness incisal bite force compared with denture adhesive made from poly(methylvinyl-ether) and without denture adhesive.

\section{REFERENCES}

1. Zarb, George A. Boucher's prosthodontic treatment for edentulous patients. $16^{\text {th }}$ ed. Missouri: Mosby; 2016 p. 10-279.

2. Zarb GA, Bolender CL. Complete Dentures and Implant- supported Prostheses. 12th ed. New Delhi: Elsevier; 2016. p. 10-444.

3. Emami E, de Souza RF, Kabawat M, Feine JS. The impact of edentulism on oral and general health. Int J Dent 2013; 498305. DOI: 10.1155/2013/498305

4. Wooller JF, Phan HP, Dinh T, Nguyen TK, Cameron A, Öchsner A, Dao DV. Novel Low-Cost Sensor for Human Bite Force Measurement. Sensors (Basel). 2016; 16(8): 1244. DOI: 10.3390/s16081244.

5. Kimoto S, Kawai Y, Gunji A, Kondo H, Nomura T, Murakami T, Tsuboi A, et al. Study protocol for a multi-center, randomized controlled trial to develop Japanese denture adhesive guidelines for patients with complete dentures: the DentureAdhesiveGuideline trial: study protocol for a randomized controlled trial. Trials. 2016; 17(1): 506. DOI: 10.1186/s13063-016-1612-x.

6. Ahlia SC, Kumar BM, Vasanthakumar M. Mystery of Denture Adhesive-a literature review. SRM Univ J Dental Science. 2011; 2(2): 113-7.

7. Ahila SC, Kumar BM, Vasanthakumar M. Mystery of denture adhesives-a literature review. SRM university Journal of Dental Sciences. 2011; 2(2): 113-7.

8. Pachore NJ, Patel JR, Sethuraman R, Naveen YG. A comparative analysis of the effect of three types of denture adhesives on the retention of maxillary denture bases: an in vivo study. J Indian Prosthodont Soc. 2014; 14(4): 369-75. DOI: 10.1007/s13191-0130334-y.

9. Papadiochou S, Emmanouil I, Papadiochos I. Denture adhesives: a systematic review. J Prosthet Dent. 2015; 113(5): 391-7. DOI: 10.1016/j.prosdent.2014.11.001.

10. Fani M, Kohanteb J. Inhibitory activity of Aloe vera gel on some clinically isolated cariogenic and periodontopathic bacteria. Journal of Oral Science. 2012; 54: 15-21.

11. Liu C, Cui Y, Pi F, Cheng Y, Guo Y, Qian H. Extraction, Purification, Structural Characteristics, Biological Activities and Pharmacological Applications of Acemannan, a Polysaccharide from Aloe vera: A Review. Molecules. 2019; 24(8): 1554. DOI: $10.3390 /$ molecules24081554.

12. Atassi M, Ling MR, Oneglia K, Dilauro TS. A proof-of-principle bite force study using two experimental test denture adhesives and a currently marketed denture adhesive. Clin Exp Dent Res. 2020; 6(2): 266-73. DOI: $10.1002 /$ cre2.256.

13. Kalra $P$, Nadiger $R$, Shah FK. An investigation into the effect of denture adhesives on incisal bite force of complete denture wearers using pressure transducers - a clinical study. J Adv Prosthodont. 2012; 4(2): 97-102. DOI: 10.4047/ jap.2012.4.2.97.

14. Henrique BA, Aguirre Guedes O, Evaristo Ricci Volpato L, Siebert Filho G, Meireles Borba A, Zina O, Piva E, Estrela C. Physicochemical Properties of MTA and Portland Cement after Addition of Aloe Vera. Iran Endod J. 2017 Summer; 12(3): 312-7. DOI: 10.22037/iej. v12i3.10635.

15. Fuentes RM, Femenia A. Nonvitamin and nonmineral nutritional supplements. $7^{\text {th }} \mathrm{Ed}$. London: Elsevier Inc. 2019. p. 545-2. DOI: 10.1016/C2016-0-03546-5 